\title{
Investigation of the Effect of Alkali Modification of Mucin on Some Properties of Metronidazole Bioadhesive Tablets
}

\author{
*ERAGA, SO; ARHEWOH, MI.; OKOGBENIN, CO.; IWUAGWU, MA.
}

\author{
Department of Pharmaceutics and Pharmaceutical Technology, \\ Faculty of Pharmacy, University of Benin, Benin City 300001, Nigeria \\ *Corresponding author: Eraga, Sylvester $O$. \\ Tel.: +234-8030884928:
}

KEYWORDS: alkali treatment, mucin, mucoadhesion, tablets, metronidazole

\begin{abstract}
The objective of this study was to investigate the effect of alkali treatment of mucin on the mucoadhesive properties and tablet parameters of metronidazole tablets. Mucin was extracted from the African giant snails (Archachatina maginata) by differential precipitation using acetone, air-dried and pulverized. Different portion of the mucin powder was treated with mineral bases (sodium and ammonium hydroxides) and organic base (pyridine) at high and low concentrations and at varied times of 1 and $12 \mathrm{~h}$. Ten batches of metronidazole tablets (B1-B10) were prepared with the modified mucin by direct compression. Their granules and tablets were evaluated for flow properties and tablets parameters, respectively. Tablet mucoadhesion was determined using the mass flow rate method. All the batches of granules gave good flow characteristics with their angles of repose $<30^{\circ}$. The formulated tablets passed the weight variation test and had hardness values within the range of 3.2 to $5.0 \mathrm{kp}$ and friability of 0.7 to $2.0 \%$ while the content of active drug met official compendial requirements. Tablets of $1 \mathrm{M} \mathrm{NaOH}$ treated mucin for $1 \mathrm{~h}$ gave the best mucoadhesion values of $5.95 \mathrm{~g} / \mathrm{sec}$, followed by the $0.1 \mathrm{M} \mathrm{NaOH} 12 \mathrm{~h}$ treatment and $0.1 \mathrm{M}$ $\mathrm{NaOH} 1 \mathrm{~h}$ treatment with $4.34 \mathrm{~g} / \mathrm{sec}$ and $4.14 \mathrm{~g} / \mathrm{sec}$, respectively. These values were higher than those of the unmodified mucin tablets which gave $0.75 \mathrm{~g} / \mathrm{sec}$. Tablets of $0.1 \mathrm{M}$ pyridine treated mucin for $1 \mathrm{~h}$ gave the least mucoadhesion values of $0.51 \mathrm{~g} / \mathrm{sec}$. Tablets of mucin treatment using $\mathrm{NaOH}$ gave improved mucoadhesive properties compared to the unmodified mucin. Thus, $\mathrm{NaOH}$ modified mucin can be preferred in the formulation of some mucoadhesive dosage forms. (C) JASEM
\end{abstract}

\section{http://dx.doi.org/10.4314/jasem/v19i3.12}

\section{INTRODUCTION}

Mucoadhesive dosage forms has received renewed attention in the last two decades because of the benefit in prolonging the residence time of its dosage forms through various mucosal routes. These systems also promote rapid absorption and good bioavailability of drugs due to the considerable surface area and high blood flow in the mucosal regions of the body. As a result, mucoadhesive polymers whether synthetic or from natural sources continue to find increased interest in drug delivery formulations (Lavelle, 2001; El-Kamel, et al, 2002; Goswami and Sharma, 2012).

The search for newer and better polymers has led to the modification of existing polymers in a bid to enhance its inherent properties or to produce an entirely new compound with different properties. Sodium carboxymethyl cellulose, is a modified product of cellulose by the incorporation of a sodium carboxymethyl group onto its backbone resulting in a profound change in its properties (Gautam, et al., 2011). Microcrystalline cellulose and chitosan are modified products obtained from acid treatment of $\alpha$ cellulose (Oyeniyi and Itiola, 2012) and deacetylation of chitin with strong alkali, respectively (No and Meyers, 1992; Sato, et al., 2001; Ge, et al., 2004).

Mucin, a glycoprotein of animal origin, with mucoadhesive properties has been used in pharmaceutical industries as delivery aids in drug formulations (Adikwu, 2006; Adikwu, 2009), owing to its biocompatibility, non-antigenic, nontoxic as well as biodegradability in the living system.

Various forms of modification have been attempted on mucin, of which PEGylation of mucin is the most prominent (Veronese and Pasut, 2005; Kenechukwu, et al., 2013; Momoh, et al., 2013; Eraga, et al., 2015). Other modifications of mucin reported include thermal, pH, chemical, physical etc (Sarkar, et al., 1987; Viney, et al., 1993; Baranowski, 2006; Adikwu and Eraga, 2007). These modifications have been reported to affect mucin properties such as aggregation and gelation, stability, rheology, adhesiveness, crystallinity and viscosity (Bansil and Turner, 2006). Mucin also is a matrix former (Momoh, et al., 2010), this property is beneficial for incorporated drugs when the intention is for the drug to be released in a controlled or sustained manner. 
Metronidazole (2-methyl-5-nitroimidazole-1-ethanol) is an oral synthetic nitroimidazole antibiotic medication used for the treatment of infections caused by anaerobic bacteria and protozoa (Mourya, et al., 2010). The increase frequency of administration of metronidazole in conventional dosage forms tend to reduce patient compliance and also lead to increase side effect of the drugs. The potential of enhancing the bioadhesive properties of mucin with the benefit of increasing metronidazole release profile in the gastrointestinal tract and hence improve administration and absorption informs the choice of modifying mucin.

The objective of this study was to determine the effect of alkali modification of mucin on its bioadhesive properties and on some tableting parameters of metronidazole matrix tablets formulated with the modified mucin.

\section{MATERIALS AND METHODS}

Materials The materials used were procured from local suppliers without further purification. All the reagents used were of analytical grade. Metronidazole (Huang Gang Yinhe Aarti Pharmaceutical Co. Ltd, China), sodium hydroxide (Titan Biotech Ltd, India), hydrochloric acid and acetone (Merck, Germany), pyridine (May and Baker Ltd, England), methanol, lactose, magnesium stearate and talc were products of BDH Chemicals, England. Terrestrial Snails (Archachatina marginata, family - Arionidae) were purchased from a local market in Benin City, Nigeria.

Extraction of snail mucin: Mucin was extracted from the African giant land snails Archachatina marginata using the method described by Adikwu, et al., 2005. The snail shells were cracked and their fleshy bodies removed from the shells with the aid of a metal rod. Excretory materials accompanying the bodies were removed. A total weight of $100 \mathrm{~g}$ of the snail bodies was subjected to washing by squeezing off the slime from the fleshy bodies repeatedly into a pool of 250 $\mathrm{ml}$ of water and decanted. This procedure was repeated 2 more times to give a total decanted pool of 1 litre. Mucin was precipitated out of the pooled washings using $2 \mathrm{~L}$ of chilled acetone. The precipitate was filtered and lyophilized to give brownish flakes. The dried flakes were blended in an electric blender to give mucin powders. The powder was stored in an airtight container until use.

Modification of mucin powder: Modification of mucin was carried out by weighing $10 \mathrm{~g}$ of mucin powder into each of 3 beakers (B1-B3). The contents of beakers B1 and B2 were mixed with $25 \mathrm{ml}$ of 0.1 $M$ sodium hydroxide $(\mathrm{NaOH})$ solution while beaker B3 was treated with $25 \mathrm{ml} 1.0 \mathrm{M} \mathrm{NaOH}$. The beakers were allowed to stand at room temperature and the contents of B1 and B3 were neutralized after $1 \mathrm{~h}$ while that of B2 after $12 \mathrm{~h}$ with equimolar volumes of hydrochloric acid solution. The neutralized contents of the beakers were first air-dried for $24 \mathrm{~h}$ and further dried under silica gel into flakes in a desiccator. The dried flakes was pulverized into powder and stored in an airtight container until use. Similar modification procedures were carried out with ammonium hydroxide (B4, B5, B6) and pyridine (B7, B8, B9). A schematic diagram of the modification process is shown in Figure 1.

Evaluation of the modified mucin powder: Solubility profile, The solubility of a $1 \%$ dispersion of the modified mucin powders was determined in distilled water, methanol and chloroform at ambient temperature $\left(28 \pm 2{ }^{\circ} \mathrm{C}\right)$. The dispersions were allowed to stand for $24 \mathrm{~h}$ and the extent of solubility noted. $p H$ determination A $1 \%$ dispersion of the modified mucin powders was prepared with distilled water and allowed to stand for $1 \mathrm{~h}$ with the container capped at room temperature. The $\mathrm{pH}$ of the resultant solution was determined in triplicates using a digital pH meter (HI 2215, Hanna Instruments, USA).

Melting point: The modified mucin powders were packed into a capillary tube sealed on one side and tapped on a hard surface for the powders to form a column at the bottom of the capillary tube. The tube was inserted into the heating block of a Gallenkamp melting point apparatus. The temperature of the heating block was raised from room temperature at 1 ${ }^{\circ} \mathrm{C}$ per min until the sample melts. The melting temperature was recorded as the melting point. Triplicate determinations were carried out per batch.

Preparation of granules and tablets: Various batches of the modified mucin granules were prepared using dry granulation method according to the formula in Table 1. Ten (10) batches of metronidazole granules (B1-B9 and a control batch (B10) containing the unmodified mucin) were prepared using lactose as diluent. The ingredients of each batch were weighed and passed through a $710 \mathrm{~mm}$ mesh screen (Endecotts, England) prior to mixing. The screened quantities of metronidazole, mucin powders and lactose were transferred into a mortar and mixed intimately with a pestle. Specific screened quantities of magnesium stearate and talc were added stepwise and mixed thoroughly. The powder blend was slugged using a heavy-duty tableting machine (Karl Kolh Technical Supplies, Germany) and the resulting tablets were broken up into granules with a mortar and pestle. The granules were evaluated for precompression parameters.

The granules were compressed into tablets using a single punch tableting machine (Manesty Machines, UK) at a pressure of 40 arbitrary units (AU). Tablets from the various batches were evaluated for postcompression parameters. 
Granule properties: Bulk and tapped densities: A 30 $\mathrm{g}$ quantity of the granules was poured gently into a $100 \mathrm{ml}$ graduated measuring cylinder. The volume of the granules was read and the bulk density calculated. The measuring cylinder was then tapped 100 times on a wooden platform. The volume was noted and used in calculating the tapped density. Carr's index and Hausner's ratio were computed from the bulk and tapped density values obtained.

Angle of repose: The hollow tube method was used. A short hollow tube of $3 \mathrm{~cm}$ in internal diameter sitting on a circular horizontal surface of same diameter was filled with granules. The tube was withdrawn vertically and excess granules allowed to fall off the edge of the circular horizontal surface. The height of the heap was measured. The angle of repose, $\theta$, was calculated using Equation 1 .

$\theta=\tan ^{-1}(h / r) \quad 1$; Where $\mathrm{h}$ is the height of the heap of granules and $r$ is the radius of the circular base

Tablet evaluations : The following tests were carried out on the compressed tablets using standard procedures: tablet weight uniformity, friability, hardness test, content of active and dissolution rate (BP, 2003).

The weight of each of 20 tablets was determined from each batch using an electronic balance (College B154, Mettler Toledo, Switzerland) and the mean weight and standard deviation were computed. Ten weighed tablets were then placed in the drum of a friabilator (Erweka GmbH, Germany) revolving at 25 rpm which exposed the tablets to rolling and repeated shock resulting from free fall within the apparatus. After $4 \mathrm{~min}$, the tablets were brought out, dedusted and reweighed. The weight was then recorded and friability calculated as percentage loss in weight. The hardness of each of ten tablets per batch was determined (Campbell Electronics, Model HT-30/50, India). The mean hardness and standard deviation were calculated.

Content of active : Twenty (20) tablets were randomly selected from each batch and crushed to fine powder. A quantity of the powdered tablets equivalent to $200 \mathrm{mg}$ metronidazole was weighed and dissolved in about $50 \mathrm{ml}$ of $0.1 \mathrm{M} \mathrm{HCl}$ in a $100 \mathrm{ml}$ volumetric flask. The volume was made up with more $\mathrm{HCl}$ solution and allowed to hydrate for $5 \mathrm{~h}$. Necessary dilutions were carried out to obtain a final concentration of $100 \mu \mathrm{g} / \mathrm{ml}$, the solution was thereafter filtered through a Whatman No 1 filter paper and the absorbance of the filtrate determined at $275 \mathrm{~nm}$ (T70, PG Instruments Ltd, USA) using 0.1 M $\mathrm{HCl}$ solution as blank. The amount of drug was determined using the equation from the standard calibration plot obtained from pure metronidazole powder.
Dissolution studies: The dissolution profiles of the metronidazole tablets were determined using the BP basket method for the various batches of the tablets (Caleva ST7, UK). A dissolution medium of $900 \mathrm{ml}$ of $0.1 \mathrm{M} \mathrm{HCl}$ maintained at $37 \pm 1{ }^{\circ} \mathrm{C}$ with a basket revolution of $50 \mathrm{rpm}$ was used. A $5 \mathrm{ml}$ aliquot of the dissolution medium was withdrawn at various intervals and replaced with an equivalent volume maintained at same temperature $\left(37 \pm 1{ }^{\circ} \mathrm{C}\right)$ of the dissolution medium. The samples were filtered and diluted with more volume of $0.1 \mathrm{M} \mathrm{HCl}$. This was carried out until dissolution was completed. The absorbances of the resulting solutions were measured at $\lambda$ max of $275 \mathrm{~nm}$. The percentage of drug released at predetermined time interval was computed using the values obtained from the standard calibration plot for the pure drug. A minimum of triplicate determinations was carried out for all batches and the results were reported as mean $\pm \mathrm{SD}$.

Bioadhesion test

This test was carried out for each batch of tablets using the method of Attama et al., 2000 with some modification. Freshly excised albino rabbit ileum of about $10 \mathrm{~cm}$ was pinned on a plastic support at an angle of $30^{\circ}$ and a tablet was placed on the exposed hydrated mucus surface for a period of $5 \mathrm{~min}$, to allow for tablet mucus interaction and hydration. A burette was then filled with $0.1 \mathrm{M} \mathrm{HCl}$ solution and then allowed to flow over the tablet using lamina flow rate of $2 \mathrm{ml} / \mathrm{sec}$ until the tablet detaches from the excised ileum. The mass flow rate $(\mathrm{g} / \mathrm{sec})$ was then used as a measure of bioadhesion. The test was carried out in triplicates and the average values recorded.

Release kinetics: Data of in vitro release was fitted into different equations to determine the release kinetics of metronidazole from the mucoadhesive tablets. The kinetic equations used were zero order, first order, Higuchi and Korsemeyer-Peppas models to interpret the drug release mechanism from the tablets.

Statistical analysisData obtained were analysed using GraphPad InStat software version 3.10. The statistical difference of the batches parameters were subjected to the student's t-test at the $5 \%$ level of significance.

\section{RESULTS AND DISCUSSION}

Physicochemical properties: Results from the physicochemical tests on the modified mucin powders are shown in Table 2 . The solubility profiles at room temperature shows that only three batches viz; B1, B3 and B8 were soluble in methanol. There was some level of solubility of some of the batches in chloroform. There were reductions in the melting points of the modified batches with reference to the unmodified mucin which were however not significant while all the modified sample powders were alkaline in $\mathrm{pH}$. 
Granule properties: The flow properties of metronidazole granules formulated with the modified mucin powders are shown in Table 3 . The angle of repose for all the batches of granules fell within the range of $26.39^{\circ}-29.43^{\circ}$ and compressibility index was found to be in the range $5.08-39.32 \%$ while the Hausner ratio of the batches were in the range of $0.905-1.227$. Monographs specify an angle of repose between $20^{\circ}$ to $30^{\circ}$ and Hausner ratio of $<1.25$ as indicative of granules with good flow properties. This shows that the granules from all the batches exhibited good flowability.

Tablet properties: The result of some of the physicochemical parameters of the bioadhesive tablets prepared for the various batches of the active drugs is shown in Table 4. All the formulated tablets passed the weight variation test as the variation was within the British Pharmacopoeia specification (BP, 2003), i.e., that not more than two of the individual weights should deviate from the average weight by more than $\pm 5 \%$ and none should deviate by more than $\pm 10 \%$. The hardness of the entire tablets was within the range of $3.2-5.0 \mathrm{kp}$. The friability of the formulations ranged from $0.7-2.0 \%$ while the content of active drug in all the samples were within the range required by the $\mathrm{BP}$, that is, not less than $90.0 \%$ and not more than $110.0 \%$ of the labeled content (BP, 2003).

Bioadhesion: The results of bioadhesion of tablets (Table 4) showed that the batch B3 tablets gave the highest bioadhesion; this was closely followed by the B2 and B1 batches of tablets. The B7 batch of tablets prepared with mucin powders modified with $0.1 \mathrm{M}$ pyridine for $1 \mathrm{~h}$ gave the least bioadhesive value.

In vitro drug release: In-vitro drug release studies revealed differences in the release of metronidazole from the different tablet formulations as shown in Figures $2 \mathrm{a}$ and $\mathrm{b}$. There were variations in the drug release profile amongst the different batches of the tablets. None of the batches of tablets showed a rapid release profile. They all showed a steady release of their drug content after an initial 10 - 20 min delay. Batches B1, B3 and B9 released the least amount of drugs in 80 min with 70,72 and $80 \%$ of release respectively while the $\mathrm{B} 10$ batch of tablets formulated with the unmodified mucin gave the highest drug release of $100 \%$ within the same time frame.

The correlation coefficient $\left(\mathrm{r}^{2}\right)$ values of the metronidazole bioadhesive tablets are shown in Table 5 . The result indicates that the relationship between drug release and time is not linear, suggesting a first order, slow release kinetic and a diffusion controlled release mechanism.
The modification of mucin powder by alkali treatment and the formulation of mucoadhesive tablets with the modified product have been attempted in this study. Granule parameters of both the treated and untreated mucin granules show good flow properties with respect to their angles of repose. Their tablet parameters were not significantly affected by the modification process with respect to weight uniformity, hardness and drug content. Their friability values were also within acceptable range as values up to $2 \%$ have been reported for tablets prepared by direct compression. These granule and tablet findings are in line with earlier reports by Eraga et al., 2015 working on pegylated mucin tablets. Batches B3, B2 and B1 tablets showed a significant improvement in their bioadhesion when compared with the unmodified B10 batch of tablets. Their improved bioadhesion can be attributed to the effect of the specific alkali type on mucin and in this case sodium hydroxide.

The duration of modification process of 1 and $12 \mathrm{~h}$ did not yield products with significantly different bioadhesion properties but higher alkali concentrations gave product with greater bioadhesion properties. Hence resultant changes were achieved within $1 \mathrm{~h}$ of exposure to a higher concentration of the base. Sodium hydroxide specifically modified the mucin to increase bioadhesion due to higher equimolar reactivity when compare to ammonium hydroxide and pyridine. It should however, be noted that alkali treatment did not destroy the observable granules and tableting properties of mucin from this present investigation.

The in vitro pattern of release of drugs from the mucoadhesive tablets suggests that the modified products of the various batches of tablets seem to confer some degree of retardation on drug release, a quality that is ideal for sustained release formulations. But the mechanism and kinetics of drug release showed no obvious change in pattern. The $R^{2}$ (correlation coefficient) values of the bioadhesive tablets suggests a slow release kinetic and a diffusion controlled release mechanism. This is in line with Higuchi, 1963 who in analyzing the mechanism of drug release from matrices, postulated two processes that usually prevail; dissolution controlled and diffusion controlled mechanisms.

In hydrophilic matrices, the tablets swelled when they came in contact with moisture. In this study, penetration of water into the tablet and diffusion of dissolved drug out or through the gelled layer are the two limiting processes of drug liberation from matrices (Bamba, et al., 1979), accounting for the initial lag that was observed during dissolution.

Conclusion: This study shows that alkali treatment of mucin powder using sodium hydroxide affects its 
bioadhesive property. Tablets prepared from mucin modified with sodium hydroxide showed an improved mucoadhesive activity over and above the unmodified mucin Thus, this knowledge can be improved upon to enhance the formulation of mucoadhesive pharmaceutical dosage forms using sodium hydroxide modified mucin as matrix former.

Table 1: Formula for the preparation of metronidazole mucoadhesive matrix granules/tablets

\begin{tabular}{lll}
\hline Ingredients & $\begin{array}{l}\text { Quantity/Tablet } \\
(\mathrm{mg})\end{array}$ & $\begin{array}{l}\text { Quantity/Batch } \\
(\mathrm{g})\end{array}$ \\
\hline Metronidazole & 200 & 20 \\
Mucin & 200 & 20 \\
Lactose & 100 & 10 \\
Magnesium stearate & 25 & 2.5 \\
Talc & 25 & 2.5 \\
\hline
\end{tabular}

Acknowledgement: The authors acknowledge the technical support received from the laboratory staff of the Department of Pharmaceutics and Pharmaceutical Technology, Faculty of Pharmacy, University of Benin, Benin City, Nigeria.

Table 2: Some physiochemical parameters of the modified mucin powders

\begin{tabular}{lllccc}
\hline Batch & & Solubility & \multicolumn{3}{c}{ Melting } \\
& Methanol & Chloroform & Water & point \\
B1 & ++ & + & - & 84 & 8.33 \\
B2 & - & - & - & 87 & 7.56 \\
B3 & ++ & + & - & 86 & 8.00 \\
B4 & - & - & - & 82 & 7.57 \\
B5 & - & - & - & 80 & 7.40 \\
B6 & - & - & - & 85 & 7.45 \\
B7 & - & + & - & 83 & 8.10 \\
B8 & ++ & + & - & 85 & 8.50 \\
B9 & - & - & - & 87 & 7.90 \\
\hline
\end{tabular}

- (-) Not soluble, $(+)$ sparingly soluble, $(++)$ soluble .

Table 3: Flow and bulk properties of formulated metronidazole bioadhesive granules

\begin{tabular}{cccccc}
\hline Batch & $\begin{array}{c}\text { Bulk } \\
\text { Density } \\
\left(\mathbf{g} / \mathbf{c m}^{\mathbf{3}}\right)\end{array}$ & $\begin{array}{c}\text { Tapped } \\
\text { Density } \\
\left(\mathbf{g} / \mathbf{c m}^{\mathbf{3}}\right)\end{array}$ & $\begin{array}{c}\text { Carr's } \\
\text { Index } \\
(\mathbf{\%})\end{array}$ & $\begin{array}{c}\text { Hausner } \\
\text { Ratio }\end{array}$ & $\begin{array}{c}\text { Angle of } \\
\text { Repose } \\
\left({ }^{\circ}\right)\end{array}$ \\
\hline B1 & $0.6429 \pm 0.08$ & $0.7026 \pm 0.09$ & $8.49 \pm 0.11$ & $0.9048 \pm 0.12$ & $29.17 \pm 0.30$ \\
B2 & $0.5120 \pm 0.05$ & $0.8438 \pm 0.02$ & $39.32 \pm 0.88$ & $1.6480 \pm 0.18$ & $26.39 \pm 0.51$ \\
B3 & $0.6750 \pm 0.02$ & $0.7480 \pm 0.08$ & $6.68 \pm 0.90$ & $1.0989 \pm 0.08$ & $27.80 \pm 1.01$ \\
B4 & $0.6856 \pm 0.10$ & $0.7520 \pm 0.05$ & $8.83 \pm 0.01$ & $1.0968 \pm 0.16$ & $28.49 \pm 0.61$ \\
B5 & $0.6210 \pm 0.05$ & $0.7621 \pm 0.05$ & $18.51 \pm 0.51$ & $1.2272 \pm 0.04$ & $29.43 \pm 0.45$ \\
B6 & $0.6852 \pm 0.03$ & $0.7550 \pm 0.03$ & $9.25 \pm 0.11$ & $1.1019 \pm 0.22$ & $28.89 \pm 0.41$ \\
B7 & $0.6510 \pm 0.09$ & $0.7018 \pm 0.10$ & $5.08 \pm 0.31$ & $1.0780 \pm 0.10$ & $27.10 \pm 0.61$ \\
B8 & $0.6303 \pm 0.04$ & $0.7264 \pm 0.04$ & $13.23 \pm 0.61$ & $1.1525 \pm 0.05$ & $27.52 \pm 0.80$ \\
B9 & $0.6518 \pm 0.06$ & $0.7442 \pm 0.07$ & $12.42 \pm 0.80$ & $1.1418 \pm 0.14$ & $28.07 \pm 0.45$ \\
B10 & $0.6357 \pm 0.02$ & $0.7026 \pm 0.10$ & $9.52 \pm 0.40$ & $1.1050 \pm 0.04$ & $29.17 \pm 0.01$ \\
\hline
\end{tabular}

Values are mean \pm standard deviation

Table 4: Some physicochemical parameters of the different batches of tablets formulated

\begin{tabular}{cccccc}
\hline Batch & $\begin{array}{c}\text { Weight } \\
\text { Uniformity } \\
(\mathbf{g})\end{array}$ & $\begin{array}{c}\text { Hardness } \\
(\mathbf{k p})\end{array}$ & $\begin{array}{c}\text { Friability } \\
(\boldsymbol{\%})\end{array}$ & $\begin{array}{c}\text { Content } \\
\text { of Drug } \\
(\boldsymbol{\%})\end{array}$ & $\begin{array}{c}\text { Bioadhesion } \\
(\mathbf{g} / \mathbf{s e c})\end{array}$ \\
\hline B1 & $0.544 \pm 0.005$ & $4.20 \pm 0.035$ & $0.69 \pm 0.007$ & $98.0 \pm 0.11$ & $4.14 \pm 0.40$ \\
B2 & $0.546 \pm 0.013$ & $4.10 \pm 0.035$ & $1.89 \pm 0.012$ & $99.0 \pm 0.25$ & $4.34 \pm 1.10$ \\
B3 & $0.534 \pm 0.004$ & $3.20 \pm 0.260$ & $1.25 \pm 0.004$ & $98.5 \pm 0.21$ & $5.95 \pm 0.90$ \\
B4 & $0.543 \pm 0.010$ & $4.30 \pm 0.073$ & $2.00 \pm 0.059$ & $97.8 \pm 0.12$ & $1.07 \pm 0.99$ \\
B5 & $0.550 \pm 0.007$ & $4.50 \pm 0.108$ & $1.98 \pm 0.009$ & $100.4 \pm 0.24$ & $1.40 \pm 1.45$ \\
B6 & $0.545 \pm 0.007$ & $4.10 \pm 0.079$ & $1.29 \pm 0.005$ & $97.4 \pm 0.22$ & $0.51 \pm 0.80$ \\
B7 & $0.536 \pm 0.003$ & $4.00 \pm 0.124$ & $1.23 \pm 0.007$ & $100.2 \pm 0.28$ & $0.86 \pm 0.50$ \\
B8 & $0.559 \pm 0.007$ & $4.00 \pm 0.074$ & $1.25 \pm 0.007$ & $98.5 \pm 0.10$ & $1.71 \pm 1.22$ \\
B9 & $0.546 \pm 0.008$ & $4.20 \pm 0.074$ & $1.25 \pm 0.005$ & $99.0 \pm 0.10$ & $0.75 \pm 0.85$ \\
B10 & $0.551 \pm 0.010$ & $5.00 \pm 0.080$ & $0.7 \pm 0.008$ & $98.5 \pm 0.20$ & $0.70 \pm 0.50$ \\
\hline
\end{tabular}

Values are mean \pm standard deviation

Table 5: Correlation coefficient $\left(r^{2}\right)$ of the dissolution studies

\begin{tabular}{|c|c|c|c|c|}
\hline \multirow[t]{3}{*}{ Batch } & \multirow{2}{*}{$\frac{\text { Release kinetic }}{\text { Zero order }}$} & \multirow[b]{2}{*}{ First order } & \multirow[b]{2}{*}{ Higuchi } & \multirow[b]{2}{*}{$\begin{array}{l}\text { Korsemeyer- } \\
\text { Peppas }\end{array}$} \\
\hline & & & & \\
\hline & $\mathbf{r}^{2}(\mathbf{n})$ & & & \\
\hline B1 & 0.9438 & 0.9558 & 0.9876 & $0.9478(10.807)$ \\
\hline B2 & 0.9423 & 0.9680 & 0.9542 & $0.9698(11.775)$ \\
\hline B3 & 0.9244 & 0.9348 & 0.9871 & $0.9302(14.475)$ \\
\hline B4 & 0.9618 & 0.9683 & 0.9362 & 0.9395 (15.674) \\
\hline B5 & 0.9631 & 0.9799 & 0.9347 & 0.9669 (13.697) \\
\hline B6 & 0.9584 & 0.9812 & 0.9155 & $0.9669(12.520)$ \\
\hline B7 & 0.9458 & 0.9741 & 0.7308 & $0.9753(12.037)$ \\
\hline B8 & 0.9314 & 0.9614 & 0.9936 & $0.9695(08.627)$ \\
\hline B9 & 0.9615 & 0.9769 & 0.9877 & 0.9567 (11.572) \\
\hline B10 & 0.9310 & 0.9354 & 0.8144 & $0.9124(18.423)$ \\
\hline
\end{tabular}




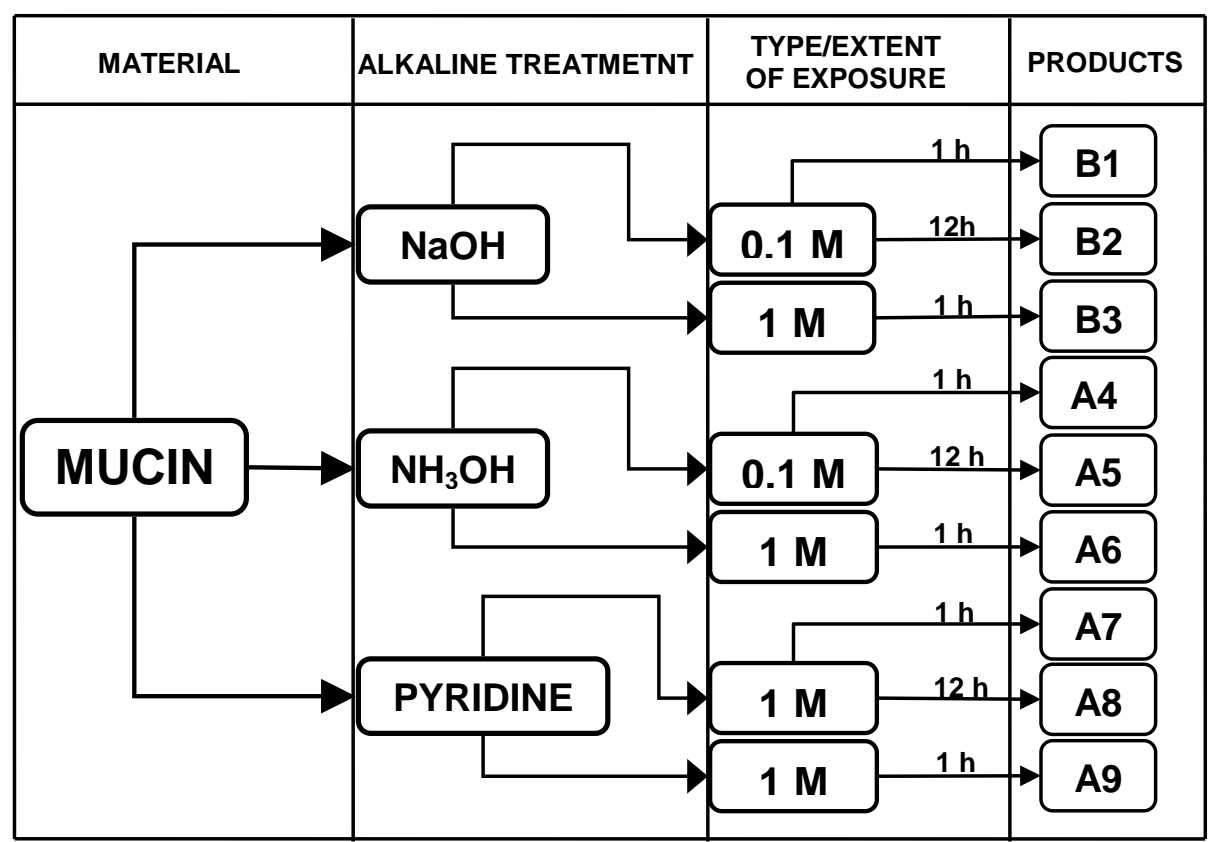

Fig 1: A Schematic diagram of the alkali treatment processes
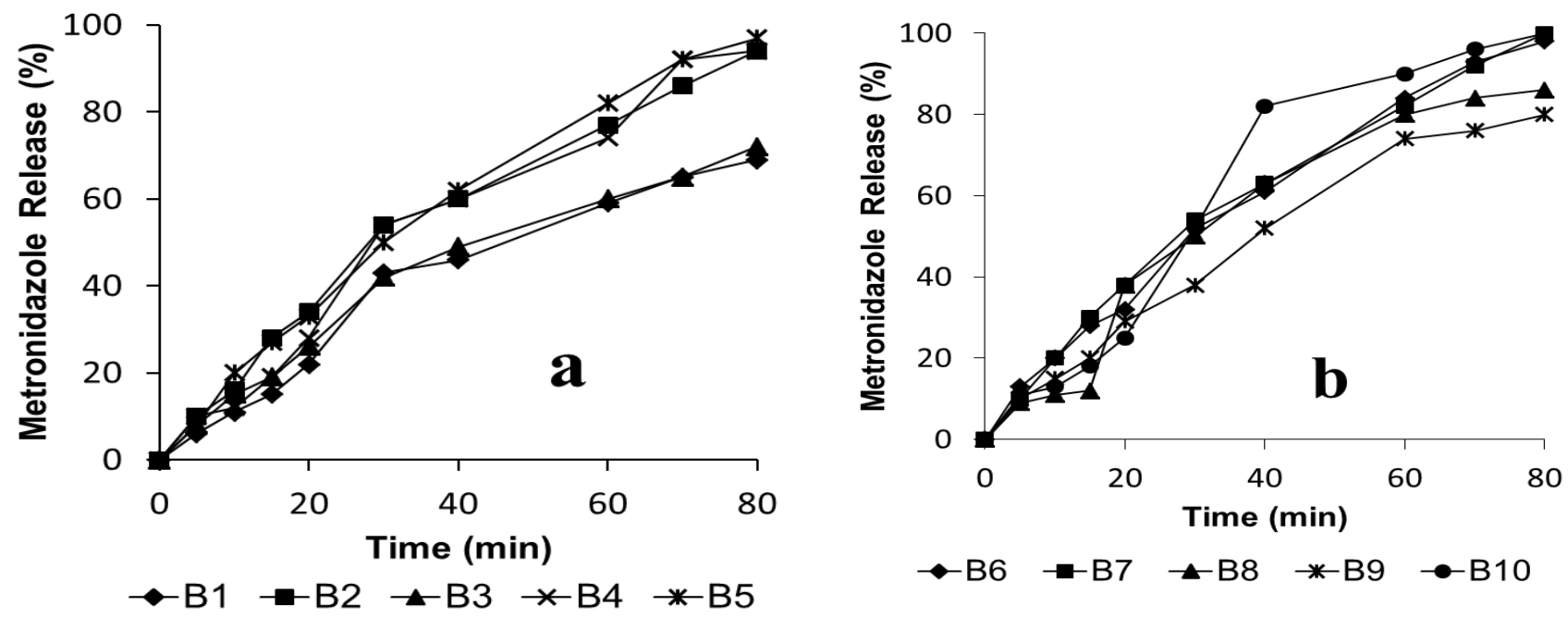

Fig2a \& b: Dissolution profile of the metronidazole tablets

\section{REFERENCES}

Adikwu, MU; Aneke, KO (2005). Builders PF. Biophysical properties of mucin and its use as a mucoadhesive agent in drug delivery: Current developments and future concepts. Nig J Pharm Res 4: 60-69.

Adikwu, MU; Eraga, SO (2007). Evaluation of the stability and rectal absorption of insulin-mucin complex. Res Rev Biosci 1(3): 111-118.

Adikwu, MU (2009). Multifarious potentials of tropical animal-derived biopolymer in drug delivery: Lesson from the African snail mucin.
In: Biopolymers in Drug Delivery: Recent Advances and Challenges, Bentham Science Publishers, Sharjah, UAE. pp. 27-38.

Adikwu, MU (2006). Mucin and their potentials. Trop J Pharm Res 5: 581-582.

Attama, AA; Adikwu, MU; Okoli, ND (2000). Studies on bioadhesive granules I: Granules formulated with Prosopsis africana (Prosopsis) gum. Chem Pharm Bull 48: 734-737. 
Bamba, M; Puiseux, JP; Marty, JP; Carstensen, JT (1979). Physical model for release of drug from gel forming sustained release preparations. Int $\mathbf{J}$ Pharm 3: 87-92.

Bansil, R; Turner, BS (2006). Mucin structure, aggregation, physiological functions and biomedical applications. Curr Opin Colloid Interface Sci 11: 164-170.

Baranowski, WJ (2006). UV-VIS spectra of intestinal mucins with change in solution concentration and pH. Adv Clin Exp Med 15(2): 253-258.

British Pharmacopoeia (2003). Vol. I and II. The Pharmaceutical Press, Her Majesty's Stationer Office, London. pp. 249-252.

El-Kamel, A; Sokar, M; Naggar, V; Al Gamal, S (2002). Chitosan and sodium alginate-based bioadhesive vaginal tablets. AAPS Pharm Sci 4: 224-230.

Eraga, SO; Arhewoh, MI; Iwuagwu, MA; Ukponahiusi, OE (2015). Formulation and invitro release studies of pegylated mucin based matrix tablets. Pak J Pharm Sci 28(1): 113-118.

Gautam, S; Ashoke, S; Sagar, P (2011). Grafted Polysaccharides: Smart Materials of the Future, Their Synthesis and Applications. In: Susheel K and Luc A (eds.) Biopolymers: Biomédical and Environmental Applications. Scrivener Publishing, Massachusetts. pp. 99-128.

Ge, Z; Baguenard, S; Lim, LY; Wee, A; Khor, E (2004). Hydroxyapatite-chitin materials as potential tissue engineered bone substitutes. Biomaterials 25: 1049-1058.

Goswami, DS; Sharma, M (2012). Development of new mucoadhesive polymer from natural source; Asian J Pharm Clin Res 5: 247-250.

Higuchi, T (1963). Mechanism of sustained action medication: Theoretical analysis of rate of release of solid drugs dispersed in solid matrices. J Pharm Sci 52: 1145-1149.

Kenechukwu, FC; Ibezim, EC; Attama, AA; Momoh, MA; Ogbonna, JDN; Nnamani, PO; Chime, SA; Umeyor, CE; Uronnachi, EM (2013). Preliminary spectroscopic characterization of PEGylated mucin, a novel polymeric drug delivery system. Afr J Biotechnol 12(47): 66616671.
Lavelle, EC (2001). Targetted delivery of drugs to the gastrointestinal tract. Crit Rev Ther Drug Carrier Syst 18: 341-386.

Momoh, MA; Adedokun, MO; Adikwu, MU; Kenechukwu, FC; Ibezim, EC; Ugwoke, EE (2013). Design, characterization and evaluation of PEGylated-mucin for oral delivery of metformin hydrochloride Afr J Pharm Pharmacol 7(7): 347-355.

Momoh, MA; Adikwu, MU; Ibezim, EC (2010). Formulation and evaluation the bioadhesive properties of drug delivery system based on PEGylated mucin matrices. Asian Pac J Trop Med 3(6): 461-464.

Mourya, DK; Malviya, R; Bansal, M; Sharma, PK (2010). Formulation and release characteristics of novel monolithic hydroxyl propyl methyl cellulose matrix tablets containing metronidazole. Int J Pharma Bio Sci 1(3): 3-4.

No, HK; Meyers, SP (1992). Utilization of crawfish processing wastes as carotenoids, chitin, and chitosan sources. J Korean Soc Food Nutr 21(3): 319-326.

Oyeniyi, YJ; Itiola, OA (2012). The physicochemical characteristic of microcrystalline cellulose derived from sawdust, agricultural waste products. Int J Pharm Pharm Sci 4(1): 197-200.

Sarkar, M; Mitra, D; Sen, AK (1987). Studies on chemical modification of cold agglutinin from the snail Achatina fulica. Biochem J 246: 157161 .

Sato, T; Ishii, T; Okahata, Y (2001). In vitro gene delivery mediated by chitosan. Effect of $\mathrm{pH}$, serum and molecular mass of chitosan on the transfection efficiency. Biomaterials 22(15): 2075-2080.

Veronese, FM; Pasut, G (2005). PEGylation, successful approach to drug delivery. Drug Discov Today 10(21): 1451-1458.

Viney, C; Huber, A; Verdugo, P (1993). Liquidcrystalline order in mucus. Macromolecules 26(4): 852-5. 